\title{
A STUDY ON FRACTURE TOUGHNESS OF ULTRA-HIGH TOUGHNESS GEOPOLYMER COMPOSITES BASED ON DOUBLE-K CRITERION
}

\author{
Xiaomei Wan $(1,2)$, Chen Shen (1) and Tiejun Zhao $(1,2)$ \\ (1) School of Civil Engineering, Qingdao University of Technology, China \\ (2) Cooperative Innovation Centre of Engineering Construction and Safety in Shandong Blue \\ Economic Zone, Qingdao University of Technology, China.
}

\begin{abstract}
Ultra-high toughness geopolymer composites (UHTGC) were fabricated based on the matrix of binder composed of alkali-activated fly-ash and granulated blast furnace slag and polyvinyl alcohol (PVA) fibres in this research. The tensile behaviour and fracture toughness of UHTGC are investigated on both macro and microscales experimentally and analyzed based on Double-K Criterion. With slag content of $20 \%$ and curing temperature $\geq 60{ }^{\circ} \mathrm{C}$, the average strain of the composite under uniaxial tension load is more than $3 \%$. Both initial fracture toughness and unstable fracture toughness of geopolymer is improved by adding PVA fibers. The fracture energy of UHTGC is up to 77 times than that of mix proportions without fibre. The results of nanoindentation test verified that the modulus of elasticity increases with curing temperature, while the fracture energy decreases slightly with curing temperature.
\end{abstract}

Keywords: Fracture energy, Toughness, Geopolymer, Double-K Criterion; Nanoindentation test, Sustainability

\section{INTRODUCTION}

Ultra-high toughness geopolymer composites (UHTGC), firstly proposed by Ohno in 2014 [1], is a new type of building material with sustainable and high performance. It is a class of geopolymer-based materials typically reinforced with polyvinyl alcohol (PVA) fibers. The significantly feature of UHTGC is that it utilizes a large amount of industrial waste to make it more suitable for the situation of global energy saving and emission reduction, while it also shows high ductility. From the viewpoint of structural design, the strain hardening ability in tension and flexural toughness is often referred to as the most relevant feature of UHTGC. 
On the basis of SHCC research, there are more and more theoretical studies on UHTGC recently. Ohno et al. [1] found that the maximum crack width of UHTGC is $117 \mu \mathrm{m}$ and the average crack width is $45 \mu \mathrm{m}$ even at high tensile strain level (4.5\%). UHTGC with pseudo-strain hardening behavior and multiple micro-crack under tension load was obtained. Nematollahi et al. [2-3] concluded that in a certain range, the decrease of alkali/binder ratio results in the increase of initial cracking strength, ultimate tensile strength and tensile strain capacity of UHTGC. Both Na-based and K-based activated engineering geopolymer composites exhibit strain hardening behavior, and the feasibility of UHTGC is verified.

The mechanical properties and fracture properties of a PVA fiber reinforced geopolymer composites (FRGC) were studied in this paper and part of them exhibit ultra-high toughness. The strain-stress curves of FRGC under tensile loads were obtained experimentally. Fracture toughness is evaluated by three-point bending test of notched beam. Fracture toughness index and fracture energy are calculated based on double-K fracture criterion. Additionally, the micro-mechanical properties of the materials were characterized by nanoindentation test. And the effects of the ratio of fly ash to slag and different curing temperatures on the mechanical and fracture properties of this composite are also discussed.

\section{EXPERIMENTAL PROGRAMME}

\subsection{Materials}

A Grade I ash (FA) and a S95 granulated blast furnace slag (GBFS) were selected as binding materials, whose chemical compositions are given in Table 1 and Table 2. A mixture of water glass and sodium hydroxide solution was prepared as activator. In this experiment, the modulus of water glass is 1.8 , and the content of sodium oxide is $9 \%$. The water glass is provided by Qingdao Bay Solver Chemical Co., Ltd. The selected fine aggregates are quartz sand with a maximum particle size of $600 \mu \mathrm{m}$. High modulus PVA fibers produced by KURARAY Co., Ltd are used in this experiment. The properties are shown in Table 3.

Six series of specimen with different mix proportion were prepared. The mass ratio of alkaline solution to cementitious material is 0.35 . The mix proportions are shown in Table 4 .

Table 1: Chemical composition of fly ash, wt \%

\begin{tabular}{|c|c|c|c|c|c|c|c|c|}
\hline $\mathrm{SiO}_{2}$ & $\mathrm{Al}_{2} \mathrm{O}_{3}$ & $\mathrm{Fe}_{2} \mathrm{O}_{3}$ & $\mathrm{CaO}$ & $\mathrm{TiO}_{2}$ & $\mathrm{~K}_{2} \mathrm{O}$ & $\mathrm{SO}_{3}$ & $\mathrm{ZnO}$ & $\mathrm{Na}_{2} \mathrm{O}$ \\
\hline 39.99 & 25.43 & 16.93 & 8.59 & 2.17 & 2.12 & 1.26 & 1.03 & 0.54 \\
\hline
\end{tabular}

Table 2: Chemical composition of GBFS.

\begin{tabular}{|c|c|c|c|c|c|c|c|c|}
\hline $\mathrm{CaO}$ & $\mathrm{SiO}_{2}$ & $\mathrm{Al}_{2} \mathrm{O}_{3}$ & $\mathrm{MgO}$ & $\mathrm{TiO}_{2}$ & $\mathrm{SO}_{3}$ & $\mathrm{Fe}_{2} \mathrm{O}_{3}$ & $\mathrm{MnO}$ & $\mathrm{Na}_{2} \mathrm{O}$ \\
\hline 57.11 & 22.53 & 10.98 & 3.36 & 1.87 & 1.77 & 0.91 & 0.47 & 0.21 \\
\hline
\end{tabular}

Table 3: Properties of PVA fiber.

\begin{tabular}{|c|c|c|c|c|c|}
\hline $\begin{array}{c}\text { Nominal } \\
\text { strength }^{\mathrm{a}}(\mathrm{MPa})\end{array}$ & $\begin{array}{c}\text { Diameter } \\
(\mu \mathrm{m})\end{array}$ & $\begin{array}{c}\text { Length } \\
(\mathrm{mm})\end{array}$ & $\begin{array}{c}\text { Young's modulus } \\
(\mathrm{GPa})\end{array}$ & $\begin{array}{c}\text { Elongation } \\
(\%)\end{array}$ & $\begin{array}{c}\text { Oil coating } \\
(\%)\end{array}$ \\
\hline 1620 & 39 & 12 & 42.8 & 6.0 & 0.8 \\
\hline
\end{tabular}

${ }^{\mathrm{a}}$ Apparent fiber strength is $1092 \mathrm{MPa}$. 
Table 4: Mix proportions of specimens.

\begin{tabular}{|c|c|c|c|c|c|}
\hline \multirow[b]{2}{*}{ Mix } & \multicolumn{2}{|c|}{ Binder } & \multirow[b]{2}{*}{$\begin{array}{l}\text { Sand } \\
(w t \%)\end{array}$} & \multirow[b]{2}{*}{$\begin{array}{c}\text { Activator ( } \\
\left.\mathrm{wt}^{0} \%\right)\end{array}$} & \multirow[b]{2}{*}{$\begin{array}{c}\text { Fiber } \\
(\mathrm{v} / \mathrm{v} \%)\end{array}$} \\
\hline & $\begin{array}{c}\text { Fly ash ( } \\
\text { wt } \%)\end{array}$ & $\begin{array}{c}\text { Slag ( wt } \% \\
\text { ) }\end{array}$ & & & \\
\hline M1 & 0.8 & 0.2 & 0.3 & 0.35 & 2 \\
\hline M2 & 0.8 & 0.2 & 0.3 & 0.35 & 0 \\
\hline M3 & 0.6 & 0.4 & 0.3 & 0.35 & 2 \\
\hline M4 & 0.6 & 0.4 & 0.3 & 0.35 & 0 \\
\hline M5 & 0 & 1 & 0.3 & 0.35 & 2 \\
\hline M6 & 0 & 1 & 0.3 & 0.35 & 0 \\
\hline
\end{tabular}

\subsection{Specimens fabrication}

After proper mixing, the mixes were cast into dumbbell moulds and $40 \mathrm{~mm} \times 40 \mathrm{~mm} \times 160$ $\mathrm{mm}$ prism moulds. The specimens with molds were then placed under different temperatures $\left(20^{\circ} \mathrm{C}, 60{ }^{\circ} \mathrm{C}\right.$ and $80{ }^{\circ} \mathrm{C}$ ) for 12 hours. Then the specimens were demolded and cured in a humidity cabinet at $65 \pm 5 \%$ relative humidity and $20 \pm 2{ }^{\circ} \mathrm{C}$ temperature until to 28 days.

\subsection{Uniaxial tension tests}

In order to obtain the stress-strain curve, dumbbell specimens are selected to carry out direct tensile test under external clamping on the electronic tensile testing machine, SHIMADZU AG-IS, with the maximum load of $250 \mathrm{kN}$ and the loading rate of $0.05 \mathrm{~mm} / \mathrm{min}$. Dimensions of dumbbell-shaped specimens were prepared for uniaxial tensile test. LVDT is fastened to both sides of the test area and connected to the computer for data acquisition. The tensile properties and hardening behavior of specimens with different mix proportion and curing condition were analyzed based on the stress-strain curves obtained.

\subsection{Bending tests}

In order to obtain the parameters for calculating fracture toughness and fracture energy, three-point bending tests of notched beams were carried out. The specimens with the size of $40 \mathrm{~mm} \times 40 \mathrm{~mm} \times 160 \mathrm{~mm}$ with reserved cracks of $20 \mathrm{~mm}$ in height and $1 \mathrm{~mm}$ in width in span center. Three-point bending tests were performed under the electronic universal testing machine with the loading rate of $0.1 \mathrm{~mm} / \mathrm{min}$. In addition to measuring mid-span deflection by LVDT, the crack opening of the specimen is measured by the clip extensometer at the bottom. P-CMOD curve and load-deflection curve were obtained, and the fracture related parameters were calculated accordingly.

\subsection{Nanoindentation tests}

The nanoindentation samples were prepared when the specimens were cured for 28 days. The specimens were crushed into $10 \mathrm{~mm}$ pieces, soaked in alcohol for 24 hours. After being dried, the samples were cold inlaid with epoxy resin, and then grinded with a grinder. The mesh number of grinding papers is 800, 1500, 2000, 2500 and 3000 in turn, and the grinded time is 1 minute for each grind. After grinded, the fineness of polishing suspension is $3 \mu \mathrm{m}$ and $1 \mu \mathrm{m}$, and the polished time is 5 minutes for each sample. 
The nanoindentation instrument is Nano Indenter G200 with a triangular Berkovich diamond indenter with an angle of 65.03 between the center line and the conical surface. The duration of loading is set to $10 \mathrm{~s}$, the maximum compressive load is set to $500 \mathrm{mN}$, and both loading and unloading rates are set to $20 \mathrm{mN} / \mathrm{s}$. The distance between two measuring points is too close to interfere with the test data, so the center distance of each measuring point is not less than $200 \mu \mathrm{m}$ in this experiment.

The elastic modulus and hardness of nano-scale were obtained by nanoindentation test, and the fracture toughness of nano-scale was obtained by loading-unloading diagram.

\section{RESULTS AND DISCUSSION}

\subsection{Strain hardening behavior and ductility}

Research on strain-hardening materials has been mostly dedicated to the characterization of tensile stress-strain behavior, particularly the pseudo-strain hardening ability in tension [4]. The strain-stress curves were obtained by uniaxial tension test as shown in Figure 1.

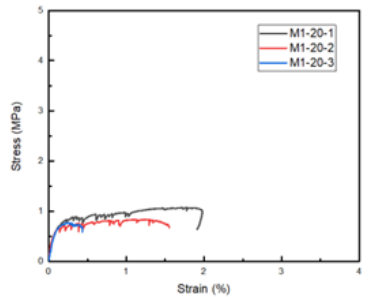

(a)

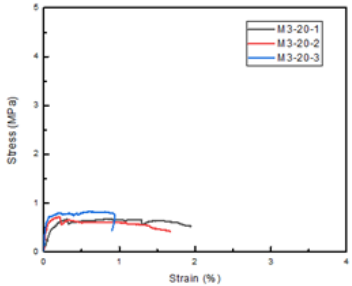

(d)

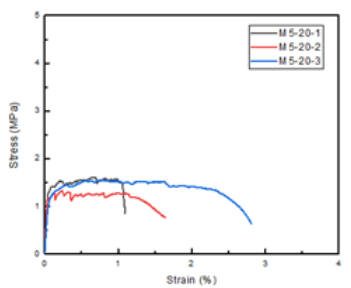

(g)

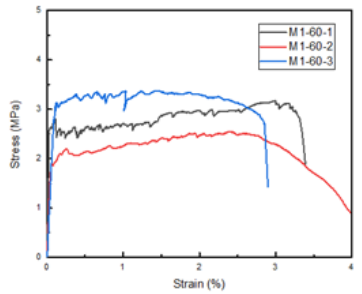

(b)

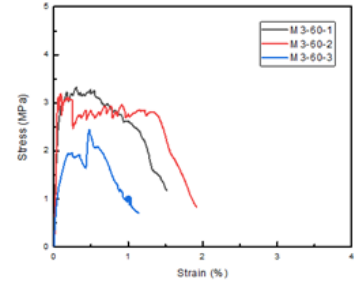

(e)

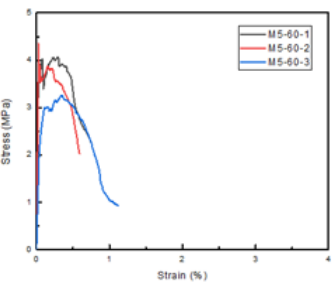

(h)

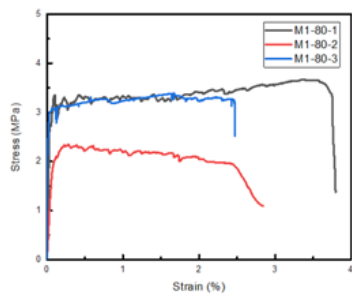

(c)

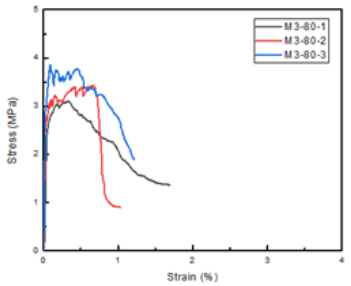

(f)

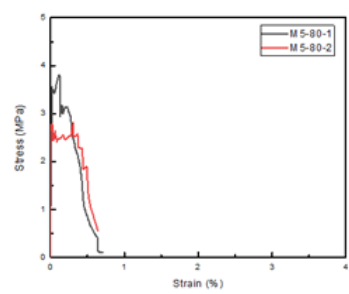

(i)

Figure 1: Strain-stress curve of specimens of different mix proportion.

The stress-strain curves of specimens with different mix proportion at the same curing temperature are compared. It was found that the strain of composites decreased gradually with the increase of slag content. This conclusion is not obvious when curing temperature is $20{ }^{\circ} \mathrm{C}$. The reason for this phenomenon is that the lower strength will show slightly better toughness, but when the strength is too low, as in Figure 1(a), the role of fiber bridging will failure to give a full play. And the stress-strain curves of specimens with the same mix proportion and different curing temperatures were compared. It was found that the strain of composites 
decreased gradually with the increase of curing temperature. When the tensile strength is high enough, the pull-out of fibers is replaced by the pull-out of fibers. When slag content is $20 \%$, the strain of composite is very high except for the one under the curing temperature of $20{ }^{\circ} \mathrm{C}$ (the strain is more than $3 \%$ ). Other mix proportions show a lower strain (from $0.5 \%$ to $2 \%$ ), but there is hardening process, nonetheless. Nevertheless, proper but not high slag content is benefit for the strain hardening of UHTGC.

\subsection{Fracture analysis based on Double-K Criterion}

The P-CMOD curves obtained from the three-point bending test of notched beams are presented in the Figure 2. The initiation crack load can be determined by P-CMOD curve. The appearance of fracture process zone at crack tip of concrete leads to the nonlinearity of the rising section of P-CMOD curve, and the turning point from linear to non-linear is defined as the initial cracking point, and the corresponding load is the initial cracking load $\left(P_{\text {ini }}\right)$.

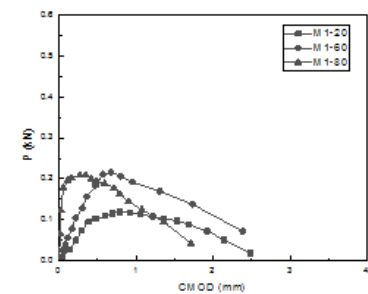

(a)

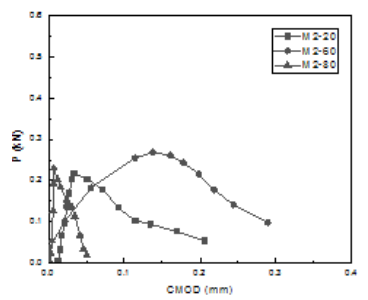

(d)

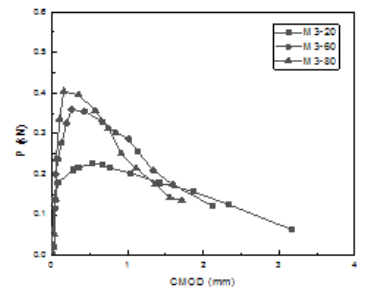

(b)

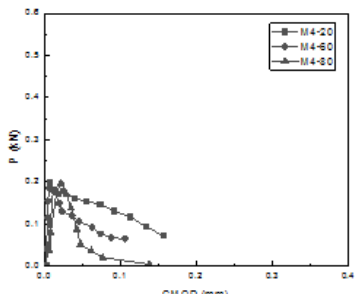

(e)

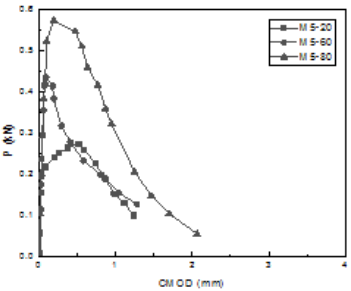

(c)

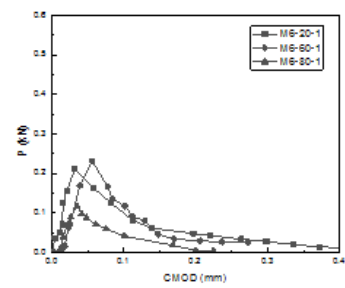

(f)

Figure 2: P-CMOD curve of mixes with $(a, b, c)$ and without fiber $(d, e, f)$.

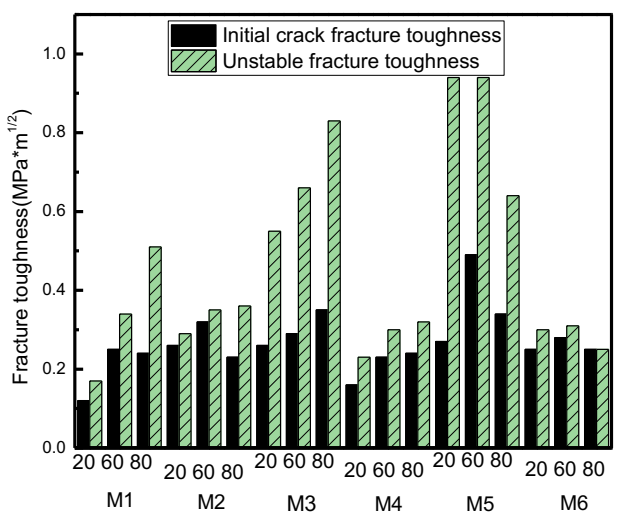

Figure 3: Fracture toughness from P-CMOD curve.

The calculation results of fracture toughness are shown in Figure 3, according to which, the initial fracture toughness and unstable fracture toughness of the specimens with PVA fibers are higher than those without fibers, while the initial fracture toughness and unstable fracture toughness of M1 specimens are slightly lower than those of other mix proportions with fiber 
(M3, M5). However, from the stress-strain curves under the tensile load, M1 group shows the largest strain, and behaves obvious hardening effect. It is due to the initial crack toughness which is a characterization of the ability of concrete to resist cracks under load. It is closely related to the strength of matrix materials.

\subsection{Fracture characteristics and parameters}

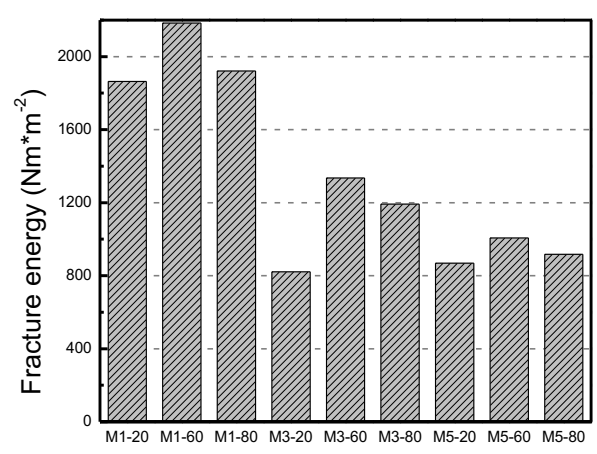

(a) With fiber

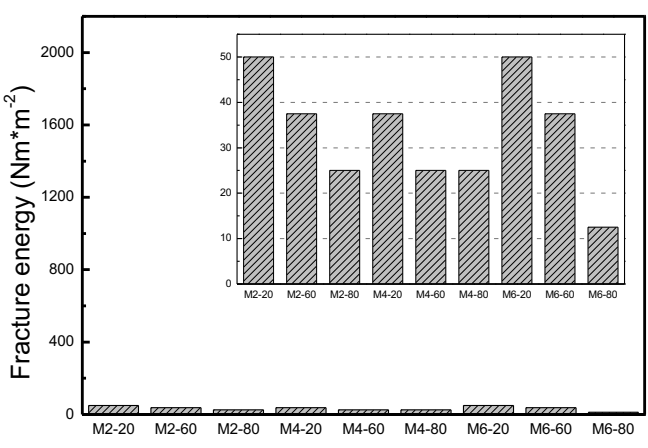

(b) Without fiber

Figure 4: Fracture energy

The fracture energy is obtained from the load-deflection curve of notched beams under three-point bending load as shown in Figure 4. It can be found that the fracture energy of the specimens with fibers is 17 to 77 times that of the specimens without fibers. For the fracture energy of non-fiber specimens, the increase of curing temperature and slag content will lead to decrease of fracture energy. But for specimens with $2 \%$ PVA fibers, the fracture energy increases with the curing temperature enhanced from $20^{\circ} \mathrm{C}$ to $60{ }^{\circ} \mathrm{C}$, while decreases with the curing temperature enhanced from $60{ }^{\circ} \mathrm{C}$ to $80{ }^{\circ} \mathrm{C}$. With the increase of slag content, the fracture energy decreases, which is consistent with the results of the specimens without fibers. Fracture energy is the energy needed to describe the development of cracks per unit area. The crack strength and deflection of the specimen itself both contribute to the value. Higher curing temperature and slag content brings higher bending strength, but also reduces ductility. Therefore, compared with other mix proportions, when the curing temperature is $60{ }^{\circ} \mathrm{C}$ and the slag content is $20 \%$, the ductility and strength are both higher, and the fracture energy is the largest.

\subsection{Results of nanoindentation}

The basic principles of nanoindentation is to press a tip indenter with known material parameters such as hardness and modulus of elasticity in to the tested material with unknown parameter to obtain the load-depth curve (P-h curve), and to obtain the mechanical parameters of the tested material through the scientific analysis of P-h curve. Reduction modulus, hardness, contact area and contact depth have been obtained through nanoindentation test.

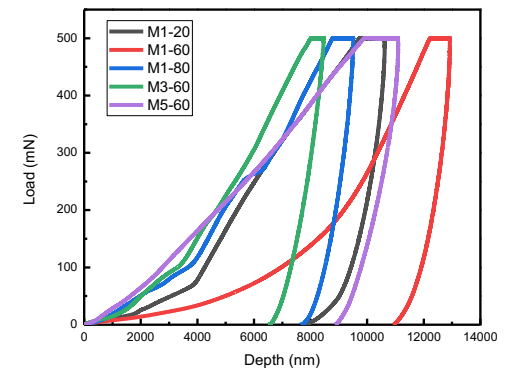

Figure 5: The load-depth curves of different mix proportions 


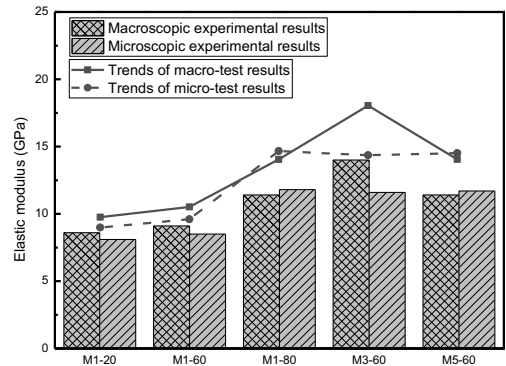

(a)

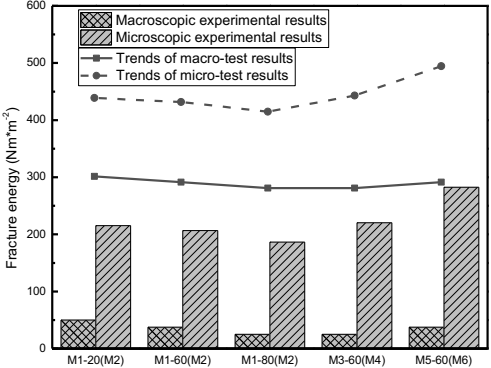

(b)

Figure 6: Elastic modulus (a) and Fracture energy (b) of different mix proportions

The load-depth curves obtained from nanoindentation are shown in Figure 5. The results of nanoindentation test are compared with those of macro-indentation test, as shown in Figure 6. It can be found that the nanoindentation results are in good agreement with the macro-test results. The modulus of elasticity increases with the increase of curing temperature. In Figure 6 , the results of nanoindentation are compared with those of each group of specimens without fibers. Since the indentation point in nanoindentation is located on the matrix, regardless with fibers, the trends of the two kind results are similar. With the increase of curing temperature, the fracture energy decreases slightly. The fracture energy obtained by three-point bending of notched beams is weaker than that obtained by nanoindentation test. It is mainly due to the anticipated size of cracks in the test of three-point bending notched beams, the damage in demoulding and the errors in the test process, which will greatly reduce the fracture energy obtained.

\section{CONCLUSIONS}

- When the slag content is $20 \%$, the curing temperature is greater than or equal to $60^{\circ} \mathrm{C}$, the average strain of the PVA fiber reinforced geopolymer composites (FRGC) under uniaxial tension load is more than $3 \%$. Increasing the amount of slag is not conducive to the increase of strain. And the increase of curing temperature has a negative effect on the increase of ductility. The ductility first increases and then decreases with the increase of curing temperature generally.

- For both initial fracture toughness and unstable fracture toughness, FRGC is higher than the mix proportion without fibers. The fracture energy of UHTGC is 17 to 77 times than that of mix proportions without fiber, and the fracture energy of UHTGC increases first and then decreases with the increase of curing temperature. For geopolymer specimens without fiber, the fracture energy decreases with curing temperature.

- The results of nanoindentation test verified that the modulus of elasticity increases with curing temperature, while the fracture energy decreases slightly with curing temperature, which are similar to those of macro-scale mechanical test results.

\section{ACKNOWLEDGEMENTS}

The authors of this contribution gratefully acknowledge support of the ongoing project of National Natural Science Foundation of China (Contract No. 51878365) and Shandong Provincial Natural Science Foundation (ZR2017MEE040). 


\section{REFERENCES}

[1] Ohno, M., and Li, V.C. A feasibility study of strain hardening fiber reinforced fly ash-based geopolymer composites. Construction and Building Materials, 57(5)(2014): 163-168.

[2] Nematollahi, B., Sanjayan, J., and Shaikh, F.U.A. Strain hardening behavior of engineered geopolymer composites: effects of the activator combination. Journal of the Australian Ceramic Society, 51(2015): 54-60.

[3] Nematollahi, B., and Sanjayan, J. 'Influence of type of fiber on tensile performance of one-part "dry-mix" strain hardening geopolymer composite (SHGC)'. In: Proceedings of The 11th fib International PhD Symposium in Civil Engineering, Tokyo, Japan, 2016.

[4] Naaman, A.E., and Reinhardt, H.W. Proposed classification of HPFRC composites based on their tensile response. Materials Structure, 39(2006): 547-555. 